\title{
AQUELARRE OU LIVRO DE MADALENA (2007), UM ESTUDO DA POÉTICA DE LUCIENE CARVALHO
}

\author{
AQUELARRE OR BOOK OF MADALENA (2007), A STUDY OF LUCIENE CARVALHO'S \\ POETRY
}

\author{
Maria Cleunice Fantinati da Silva ${ }^{1}$ \\ Elisabeth Batista ${ }^{2}$
}

Recebido: 15/04/2021

Aceito: 23/06/2021

Resumo: Sabe-se que ao longo do tempo, as escritoras mulheres foram sistematicamente excluídas do cânone literário. Entretanto, foi por meio da escrita que muitas mulheres se posicionaram criticamente conduzindo outras à reflexão. Na contemporaneidade, a escrita feminina prossegue buscando a igualdade e o reconhecimento em diversas áreas de conhecimento. Esta análise teve como objetivo averiguar qual o espaço da mulher na enunciação poética Luciênica. Assim, a proposta deste trabalho se pautou, inicialmente em tecer algumas considerações sobre os empecilhos na produção literária de feminina e, posteriormente analisar dois poemas da escritora contemporânea Luciene Carvalho. A leitura de Aquelarre ou Livro de Madalena (2007), dentre inúmeros poemas de inegável expressão poética selecionou-se uma amostra representativa para estudo e análise. Buscou-se aplicar os conceitos de Todorov (2009), Antônio Candido (2006), Leyla Perrone (2006) e Simone Beauvoir (1949). Deste modo, procurou-se entender qual o papel desempenhado pelos arquétipos da figura feminina na obra selecionada de autoria de Luciene Carvalho e, simultaneamente, analisou-se como o eu-poético se manifesta, através de seus versos, em relação a mulher no contexto sociocultural brasileiro na literatura de autoria da mulher produzida em Mato Grosso

Palavras-Chave: Luciene Carvalho; Escrita feminina; Enunciação poética.

Abstract: It is known that over time, female writers have been systematically excluded from the literary canon. However, it was through writing that many women took a critical position, leading others to reflect. Nowadays, female writing continues to seek equality and recognition in different areas of knowledge. This analysis aimed to find out what the woman's space is in Luciene's poetic enunciation. Thus, the proposal of this work was based, initially, on making some considerations about the obstacles in the literary production of feminine and, later, analyzing two poems by the contemporary writer Luciene Carvalho. A representative sample

\footnotetext{
${ }^{1}$ Doutoranda em Estudos Literários - PPGEL-(UNEMAT), Mestra em Estudos de Linguagens-Estudos Literários (UFMT). Especialização em Literatura Mato Grossense (UNEMAT). Professora - IFMT- campus avançado Tangará da Serra -MT. E-mail: maria.silva@tga.ifmt.edu.br ou fantinatiescritora@gmail.com ${ }^{2}$ Pós-doutorado Sênior pela Universidade de Aveiro (UA). Professora - PPGEL- Estudos Literários (UNEMAT). Doutorado e Mestrado em Letras (USP). E-mail: lisbatys@gmail.com
} 
was selected for study and analysis from the reading of "Avenarre or Livro de Madalena" (2007), among countless poems of undeniable poetic expression. We sought to apply the concepts of Todorov (2009), Antônio Candido (2006), Leyla Perrone (2006) and Simone Beauvoir (1949). Thus, we sought to understand the role played by the archetypes of the female figure in the selected work by Luciene Carvalho and, simultaneously, it was analyzed how the poetic-self manifests itself, through its verses, in relation to the woman in the context Brazilian sociocultural in literature authored by women produced in Mato Grosso.

Keywords: Luciene Carvalho; Female writing; Poetic enunciation.

\section{Introdução}

Em primeiro lugar torna-se essencial tecer algumas informações sobre Luciene Carvalho e a sua produção literária. Escritora, poeta e declamadora, natural de Corumbá e mudou-se com a família, ainda criança, para Cuiabá no bairro do Porto. A escritora ocupa a cadeira n ${ }^{\circ} 31$ da Academia Mato-Grossense de Letras.

O primeiro livro de Luciene, publicado pela FLAMP, é uma coletânea intitulada Devaneios Poéticos (1994). O segundo livro da escritora Luciene Carvalho é Teia (2000), seguido da publicação de Caderno de caligrafia (2003), e posteriormente a primeira edição de Porto (2005). No ano de 2007 publica Cururu e Siriri do Rio abaixo e a trilogia ContaGotas, Sumo de Lascívia e "Aquelarre ou livro de Madalena”.

Os poemas do livro Insânia (2009), considerado como fio condutor da obra Luciene escreveu em durante as internações no hospital psiquiátrico Adauto Botelho nos anos de 1995, 1998 e 2000. Ladra de Flores (2012), uma prosa poética repleta de encantos e temores feminino. Estas obras conquistaram prêmios e condecorações. A escritora também publicou um caderno de poesia para crianças, intitulado Para onde os caminhos levam (2012). Dona foi lançado em 2018. Seu último livro Na Pele (2020), produzido durante o primeiro ano da pandemia da Covid-19. Segundo a poeta, na orelha da frente de sua obra, no momento de aquilombamento nasceu-lhe o desejo de falar sobre ser preta e dialogar com os pretos da atualidade, através de seus versos. Na TV, viu estarrecida os joelhos sobre o pescoço negro impedido de respirar em sincronia com sua falta de ar pandêmica. A produção literária de Luciene Carvalho navega por diversas temáticas, mas a presença da mulher é muito forte em sua poesia.

Da trilogia lançada em 2007, por Luciene Carvalho, selecionou-se para este estudo por Aquelarre - ou o Livro de Madalena. Este livro traz o misticismo, no qual "a autora é 
instrumento - senhora e assume, em selênicos versos, a tradição guardada nos encantos, no oráculo e na fé...” MOREIRA (2007, p. 6).

O título da obra é repleto de significados. A palavra Aquelarre, segundo Moreira (2007), no prefácio do livro, no Chile possuí o sentido de reunião entre mulheres, seja em casa ou em qualquer lugar. Momento em que elas compartilham conhecimento e reverenciam a trindade feminina na donzela, na mãe e na anciã.

A segunda parte do título alude implicitamente uma das Deusas da contemporaneidade que faz a revelação de Filho de Deus ressuscitado. Na concepção de Moreira "Madalena, é uma das formas de chamar a Deusa, que também é Lilith a primeira, Maria a Mãe de Deus, Diana, Hécate, Ártemis, Isis, Mama, Oxum, Iemanjá, Nanã...”. Enfim, é a representação de todas a mulheres, ou seja, "Tantas".

A literatura nos possibilita a interação com os outros e por isso compartilha conhecimentos ampliando o nosso universo. Retomando as palavras de Todorov (2009), “a literatura não nasce no vazio, mas no centro de um discurso vivo"; assim, nasce a poética de Luciene Carvalho. Sua poesia é viva e repleta de sentidos. Seus versos livres apoderam-se das palavras que ganham movimento rítmico no cotidiano do feminino.

\title{
1. As pedras no caminho da escritora brasileira.
}

\author{
Bendicta \\ A vida vem da água, \\ vem da terra. \\ $\mathrm{O}$ ventre da mulher \\ gesta a menina e o menino. \\ A lua anda junto com as marés. \\ Por que não pode então \\ o Deus da criação \\ ser feminino? \\ (Carvalho, p.19,2007)
}

Iniciamos com o questionamento poético de Luciene Carvalho nos versos do poema "Bendicta", (2007, p.19) extraído da obra acima referenciada Nos primeiros versos observamos um elenco de palavras que, na acepção pertencem ao gênero feminino "vida, água, terra, mulher, menina lua, marés”, também afirma que o ventre da mulher gera tanto a menina quanto o menino para posteriormente indagar "Por que não pode então/ o Deus da criação/ser feminino?" 
Este verso lança uma indagação profundamente inquietante, isto porque, nós leitores, somos surpreendidos com uma nova forma de ver a criação. A autora tira-nos do lugar comum e costumeiro de que a divindade que criou o mundo é masculina. No imaginário cristão, para o senso comum, Deus é homem possui longas barbas brancas, está sentado num trono...

Para responder o eu- poético recorremos a Simone Beauvoir (p.19,1949), porque "toda a história foi feita pelos homens. No momento em que as mulheres começam a tomar parte da elaboração do mundo, esse mundo ainda é um mundo pertencente aos homens." A voz poética tem plena consciência de que toda a história da mulher foi escrita pelos homens, mas o seu questionamento vem justamente como uma provocação reflexiva para que as mulheres possam reivindicar-se como sujeitos e atuar na esfera cultural, social, histórica e política.

Na perspectiva da autora em pauta foi o homem que constitui a mulher como o "outro" e culturalmente ainda existe a aceitabilidade por parte de muitas mulheres. Conforme Beauvoir (1949, p.19), “a mulher não reivindica como sujeito porque não possui meios concretos para tanto, porque sente o laço necessário que a prende ao homem sem reclamar dele, e porque, muitas vezes, se compraz no seu papel se Outro."

Ser mulher já é o suficiente para entender que terá em seu caminho muitas pedras para remover. A mulher brasileira que tentou ou tenta se lançar no espaço literário, certamente encontrou e ainda se depara com vários obstáculos. Não obstante, a questão de ser mulher e ter a pretensão de se tornar escritora, mas ser preta e trazer consigo as marcas das injustiças históricas, esta, necessitará de forças maiores para remover e triturar as montanhas de pedras do seu caminho.

Para tecer alguns comentários sobre as dificuldades enfrentadas pela mulher negra na literatura recorremos, primeiramente, as palavras de Luciene Carvalho na entrevista concedida à Revista Balança, em agosto de 2020.

Quando lhe perguntaram quem foi o seu principal incentivador ${ }^{3}$ a escritora foi bem direta na resposta; "Ninguém. Ninguém poderia em são consciência estimular uma negra, pobre, filha de mãe viúva, a sonhar em viver de poesia, num Mato Grosso onde fazer do escritor não é considerado profissão e sim subjacência." Luciene tem plena consciência que não teve apoio de ninguém para se tornar escritora, porque "num contexto social capitalista de

\footnotetext{
${ }^{3}$ Pergunta número 6, p. 03. Entrevista com Luciene Carvalho. Na Balança, ed.2, 2020.
} 


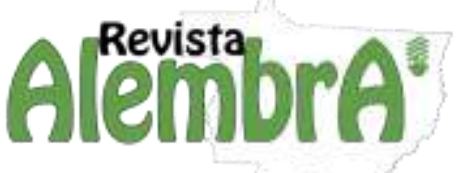

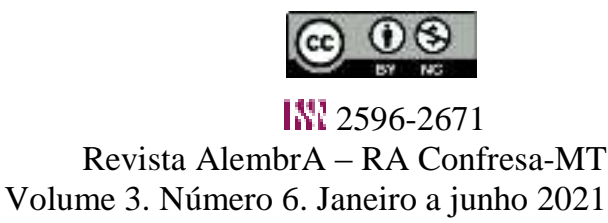

supremacia patriarcal branca com esta cultura nenhuma negra pode se tornar uma intelectual sem descolonizar a mente" (BELL HOOKS, 1995, p. 474).

Ser mulher, negra e pobre num estado em que a literatura é considerada como periférica é preciso ter coragem para se constituir como autora, sujeito da sua própria escrita. Segundo Bell Hooks (1995, p. 466), o trabalho intelectual é necessário para a luta pela libertação, sendo fundamental para os esforços de todas as pessoas oprimidas e/ou exploradas que passariam de objeto a sujeito que descolonizariam e libertariam suas mentes.

Escrever, para Luciene Carvalho, portanto, se torna uma alternativa de emancipação e consequentemente uma produção de conhecimento, assim como Kilomba (2019, p. 27), escrever foi uma forma de transformá-la, visto que se tornou sujeito de sua própria história, pois "aqui eu não sou a "Outra", mas sim eu própria. Não sou o objeto, mas o sujeito". Ser sujeito para Grada Kilomba é descrever a sua própria história e não a que é descrita, deste modo, escrever emerge um ato político. Neste sentido, a passagem do objeto a sujeito é o que marca a escrita como um ato político. Os empecilhos encontrados pela mulher na literatura emanam da política do patriarcado que torna situação dos intelectuais negros diferentes da das negras, porque:

Embora eles enfrentem o racismo não enfrentam os preconceitos de gênero. E como já se disse como são encarados como membros legítimos de uma tradição intelectual estabelecida seu trabalho é menos suspeito e muitas vezes mais recompensado que o das negras. Em consequência as intelectuais negras necessitam do apoio e estimulo de seus pares homens (BELL HOOKS, 1995, p. 475).

O patriarcado impôs suas normas rígidas para as mulheres de modo geral, mas como já comentamos, para as negras a situação foi bem mais complexa. Segundo Kilomba (2019), "devido ao racismo, as pessoas negras experienciam uma realidade diferente das brancas."

O patriarcalismo não privilegiou as mulheres de modo geral, pois elas foram consideradas como incapaz intelectualmente, a mulher foi cerceada de qualquer possibilidade de escrita e da literatura. Deste modo, a neutralizando enquanto cidadã e o direito da própria constituição enquanto sujeito participativo na história literária brasileira.

Nas perspectivas de Carvalho et.al. (2001), o tema da mulher e da relação hierárquica entre os sexos ocupa lugar importante na produção teórica contemporânea. Trata-se de um tema recorrente, visto que nas últimas décadas surgiram estudos em diversos campos do 

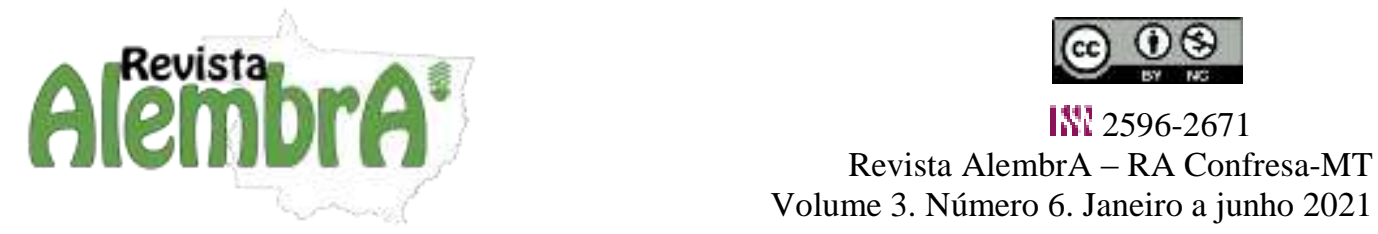

conhecimento, como por exemplo, a sociologia, o direito, a teologia e a psicologia, que contribuíram significativamente para o avanço e o tratamento sistemático da questão.

Mesmo considerando as mudanças práticas ao sexo feminino, singularmente no âmbito jurídico, a desigualdade entre os gêneros faz-se presente em todas as dimensões das relações sociais. No caso da produção literária, ao longo do tempo, as escritoras mulheres foram sistematicamente excluídas do cânone literário. Segundo Virgínia Woolf (1985), o problema começa bem antes, com a exclusão da mulher do mundo das letras e artes. Romanalli (2014), em suas pesquisas, confere que o meio literário é predominantemente branco, masculino e hétero, porque

[...] as mulheres não só foram privadas de direitos básicos como propriedade e liberdade de escolha de matrimônio, como também de alfabetização e estudo universitário. Mesmo as mulheres pertencentes às elites que eram ensinadas a ler e escrever, ainda lutavam contra muitos entraves para conseguir produzir literatura, quanto mais publicar seus textos. Algumas mulheres encontraram meios de burlar as dificuldades e preconceitos: escreviam escondidas, faziam uso de pseudônimos masculinos para serem publicadas. Mas sua participação pública e aberta no meio literário ainda era proibida (ROMANELLI, 2014, p. 44).

A condição de inferioridade era um privilégio conveniente ao patriarcalismo. Para a mulher não lhe era permitido ter voz, pois as imposições de uma sociedade machista e preconceituosa lhe tirava o direito de se pronunciar. Almeida (2014), ao apresentar Spivak ${ }^{4}$, na segunda reimpressão da obra - "Pode o subalterno falar?", diz que aquele que julga ter o poder de falar pelo outro ou por meio dele, constrói um discurso de resistência, ou seja, automaticamente reproduz as estruturas de poder e opressão, mantendo, assim, o subalterno silenciado, pois não lhe permite um lugar de onde possa falar e principalmente ser ouvido.

[...] para Spivak, se o discurso do subalterno é obliterado, a mulher subalterna encontra-se em uma posição ainda mais periférica pelos problemas subjacentes às questões de gênero. A teórica exemplifica sua crítica por meio do relato de uma história que privilegia o subalterno feminino, pois, segundo ela: "Se, no contexto da produção colonial, o sujeito

\footnotetext{
${ }^{4}$ Gayatri Chakravorty Spivak é considerada, conjuntamente com Edward Said e Homi Bhabha, uma importante representante da produção teórica pós-colonial e é, ao mesmo tempo, uma crítica feminista relevante, em termos de sua influência na produção intelectual em escala global. Nascida em Calcutta no início da década de 1940, poucos anos antes que a Índia adquirisse independência do Império Britânico, Spivak estudou literatura inglesa e bengali na Universidade de Calcutta.
} 
subalterno não tem história e não pode falar, o sujeito subalterno feminino está ainda mais profundamente na obscuridade"? (ALMEIDA, 2014, p. 17).

Estudos sobre categorias sociais apresentam as mulheres como pertencentes a grupos minoritários, ou seja, subalternizados. Entretanto, nas perspectivas de Lima, et.al (2019), as mulheres não se constituíram como um grupo social pelo fato de que sempre estiveram com os homens. Falta a elas uma história "comum" como os negros e os judeus. Entende-se que a mulher, ao logo do processo histórico, deixou-se conduzir pelo outro, ou seja, pelo homem. Porque:

Segundo Beauvoir, a figura do feminino é abordada por meio de um sujeito que não é o que a representa, mas sim outro: o masculino. O homem, desde sua infância é ensinado pelos pais também pela sociedade a serem livres. Possuem essa autonomia de empreender, inventar, ousar. Enquanto isso, para as mulheres, há um conflito entre sua existência autônoma e seu ser - o outro. Aprendem que para agradar é preciso procurar agradar, fazer-se objeto, renunciando, deste modo, a sua autonomia. [...] A história da mulher passa pelo fato, inúmeras vezes comprovado, de ser tratada como o "outro" e não como sujeito de sua própria existência (LIMA, et.al., 2019, p.108-109).

A produção poética de cunho feminino ainda encontra entraves para se colocar enquanto literatura de qualidade, pois por muito tempo pensou-se que a poesia morreu junto com os grandes poetas dos séculos passados. O grande obstáculo para esse pensamento é que a poesia não teve permissão de assumir novas formas por meio da escrita feminina. Não se pretende depreciar a produção poética de grandes escritores homens, todavia a polêmica encontra-se na forma de pensamento de alguns estudiosos de literatura que traz como noção de poesia relacionados a forma estrutural metrificada. A poesia, segundo Candido (2006), transcende os gêneros poéticos podendo haver poesia em prosa e poesia em versos livres. Embora a poesia didática do século XXIII, fosse metrificada e constituísse uma das atividades poéticas legítimas, atualmente ela está mais próxima dos valores da prosa.

A liberdade rítmica expressa nos versos modernistas, foi iniciada pelos poetas simbolistas e a simetria foi substituída pela dissonância, contraste, o efeito repentino. Assim, o metro torna-se mais livre e o poema menos regular do que os tradicionais, porque segundo Goldstein (2006, p.51), "cada poeta escolhe o ritmo que julgar adequado ao tema que vai tratar", porque mudanças no modo de vida modificam as formas artísticas. Deste modo, o ritmo inesperado, irregular, dinâmico do poema assemelha-se a vida do homem contemporâneo. 


\section{O cotidiano na poesia de Luciene Carvalho e o espaço circunscrito das Marias}

O campo poético luciênico é permeado pela voz feminina opulenta que representa a vida em seu curso e busca desconstruir a imagem da mulher frágil e contida. Há momentos em que a natureza feminina demarca o espaço, deste mundo, com imagens de tristeza, saudades e solidão. Porque a atividade poética busca relação intensa com o "mundo-da-vida" [...] BOSI,1997) e Luciene faz o poético e o percurso da vida entrelaçar, assim, temos o poema intitulado: A Mãe do Mundo

$\mathrm{Eu}$, bem pequena,

á beira do rio Paraguai

já sabia ${ }^{5}$ da Santa

não sabia de onde...

Em criança, olhei de esguelha a santinha

no colégio das irmãzinhas.

Estava ${ }^{6}$ lá, mas não vi.

Dos dias que cresci,

Olhei por catedrais,

igrejas Matrizes e capelinhas

de todo lugar que fui:

achei um certo veludo dela

e ela onde estaria?

Maria...

Me perdi. De louca. De pouca.

De dó. De adicta.

Acredita? De tudo me fantasiei.

Passei por ruas e dias

Marias...

Rezei. Rezei sempre.

Com medo. Com fé.

Rezei até com raiva.

Da palavra fiz poesia.

Tanta rima pela estrada

e a santa?

Da santa nada...

Para onde quer que eu fosse

Tinha aquela coisa doce,

Feminina divinal.

Afinal, nem sei por onde,

Fui abandonando a busca

Deixando a coisa assim:

da fé fiz banhos e mantras,

senti um conforto imenso

com minhas velas e incenso,

5 Grifo nosso. Marca o tempo verbal no pretérito perfeito do indicativo.

6 Grifo nosso. Indica a mudança do tempo verbal para o pretérito imperfeito do indicativo. 
entrei de vez no Tarô.

E em uma epifania

percebi com euforia

que a bela leminiscata ${ }^{7}$

em que o começo é o fim:

a santa que eu buscava

- isso me foi revelado-

Num esteve do meu lado,

era a deusa, mãe do mundo

e mora dentro de mim.

(CARVALHO, 2007, p. 17-18)

A relação com o mundo que fala Alfredo Bosi (1997) é perceptível neste poema intitulado "A Mãe do Mundo", pois é possível conhecer o espaço através do olhar poético de Luciene Carvalho: "Eu, bem pequena, / à beira do rio Paraguai/” [...]. (CARVALHO,2007, p.17). Percebe- se desde os primeiros versos que o tempo passou, correu, pois o eu-poético se vê bem pequena as margens do rio Paraguai e o passado é marcado através do tempo verbal: "já sabia da Santa/ não sabia de onde..."

O passado é rememorado e incorporado à teia poética mediante temporalidade verbal no pretérito perfeito do indicativo e a subjetividade poética está expressa pela primeira pessoa do singular. Novos valores são acrescentados ao poema à medida em que a memória vai sendo reativada e o passado se torna flexível podendo ser reinventado. O eu poético passa a recordar uma realidade já vivida, que por ser uma recordação, essa realidade já está no coração e, portanto, nem é mais uma realidade, e sim uma invenção.

A invenção da realidade criada para a contemplação que afirmar Todorov (2009, p. 52), pois "Graças a arte, o ser humano pode atingir o real." Entretanto, nas relações entre literatura e realidade, a mimeses foi questionada pela teoria literária que insistiu na autonomia da literatura em relação à realidade, ao referente, ao mundo. Em conformidade com Compagnon (2012), trata-se do dogma da autora referencialidade do texto literário, ou seja, a ideia de que o "poema fala do poema" e ponto final.

\footnotetext{
${ }^{7}$ Lemniscatas Esta palavra tem origem do latin e significa "Laços Simétricos". Leminiscata) é o famoso "oito deitado", tido como um símbolo do infinito. A razão de essa curva geométrica especial assumir tal significado é seu traço, contínuo, uma forma sem começo nem fim. Em matemática e em particular, Bernoulli lemniscata é um tipo de curva descrita pela seguinte equação em coordenadas cartesianas: e tem apenas dois focos. A curva tornou-se o símbolo do infinito e é amplamente utilizada em matemática.
} 
Para Leyla Perrone-Moisés, a visão do real é concebida por meio da imitação, ainda que seja uma transformação, tem o mundo como ponto de partida. Sobre a relação da literatura com o real, a autora alega a descrença na possibilidade de a linguagem representar um real prévio e elucida que "A literatura parte de um real que pretende dizer, falha sempre ao dizê-lo, mas ao falhar diz outra coisa, desvendando um mundo mais real do que aquele que pretendia dizer. [...]. O mundo é insuficiente, as palavras estão sempre em falta; mas a literatura o diz, insistente e plenamente.” (PERRONE, 2006, p. 102).

Retomando o poema, “A Mãe do Mundo" de Luciene Carvalho, nota-se nos versos que seguem um amalgamar entre realidade e invenção que surge de um tempo passado resgatado pela memória e se transfere em forma poética, pois “[...] não sabia de onde.../Em criança, olhei de esguelha a santinha/ [...]. Para onde que eu fosse/ tinha aquela coisa doce, / feminina divinal. [...]. (CARVALHO, 2007, p.17). Seria isso recordar uma meia verdade ou uma invenção? O eu-poético reinventa o tempo passado revivendo a infância, por meio da memória. A figura feminina divina representada pela Santa remete eu poético à infância, aquela coisa doce que representava o seu viver impregnado pela cultura religiosa, pois enquanto menina se fantasiou de tudo e ficou acostumada aos rituais que são repetidos até hoje às margens do rio Paraguai na cidade de Corumbá.

Na perspectiva de Bosi (1997), o tempo é que faz crescer a árvore, rebentar o botão, dourar o fruto. Na recordação é o aspecto das coisas que voltam, mas ela abre o caminho para sentir o seu ser. Assim, voz poética sente-se invadida pela figura feminina da Santa e aguardava nas margens do rio Paraguai para acompanhar as celebrações e procissões em homenagem a Santa. Segundo, Todorov (2009), a literatura refere-se a tudo. Não pode ser separada da política, da religião, da moral". O discurso poético está ligado ao mundo, deste modo, o poeta não é um resultante, nem mesmo um simples foco refletor; possui o seu próprio espelho, a sua mônada individual e única. Tem o seu núcleo e o seu órgão, através do qual tudo o que passa se transforma, porque ele combina e cria ao devolver à realidade. (CANDIDO, 2002, p. 18).

Nesta perspectiva, Candido (2002), considera a arte literária como uma transposição do real para o ilusório por meio de uma estilização formal, que pressupõe um tipo arbitrário de ordem das coisas, os seres, os sentimentos. 


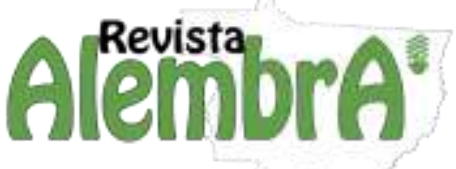

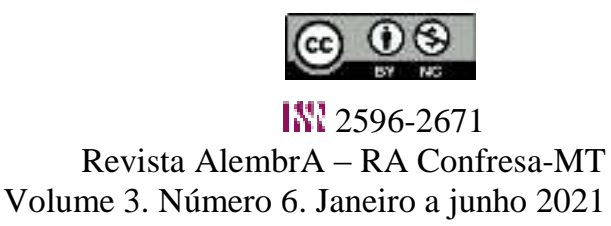

Aristóteles defendia não a veracidade, mas a verossimilhança, afirmando que o poeta não tem que narrar o que aconteceu, mas representar o que poderia ter acontecido, na perspectiva do imaginável possível. "Assim, a literatura nunca está afastada do real. Trabalhar o imaginário pela linguagem não é ser capturado pelo imaginário, mas capturar, através do imaginário, verdades do real, que não se dão a ver fora de uma ordem simbólica". (PERRONE-MOISÈS, 1990).

No verso "Estava lá, mas não vi" o eu-poético prossegue a busca pela Santa, e diz: "Dos dias que cresci, /Olhei por catedrais, / igrejas Matrizes e capelinhas/ de todo lugar que fui:/ achei um certo veludo dela/ [...]" questiona a ausência da Santa e a chama pelo nome: "e ela onde estaria? / Maria..."

Ao mudar o tempo do verbo buscar para o pretérito imperfeito do indicativo o eupoético manifesta um novo posicionamento quanto à sua religiosidade que, com decorrer do tempo, amadureceu, pois aclama: "a santa que eu buscava [...] ficou no passado. Fui abandonando a busca / Deixando a coisa assim: da fé fiz banhos e mantras, [...]. E em uma epifania / percebi com euforia/que a bela leminiscata/ o meu caminho traçou [...]". Neste momento, o eu-poético tem uma revelação e descobre que homens e mulheres não possuem os mesmos direitos na sociedade. Então se liberta da religião que lhe foi imposta, pois percebe o símbolo do infinito a partir da imagem do Oito deitado que simboliza a evolução física e espiritual sem começo e nem fim.

Percebe que a Santa que representa o modelo de mulher posto pela religião católica, nunca esteve do seu lado, e descobre que a Santa "era a deusa, mãe do mundo/e mora dentro de mim." O eu-poético estabelece o contorno figural da Deusa Mãe do Mundo ${ }^{8}$, recorrendo assim a mitologia grega para expressar a força feminina.

No poema da página 30, encontramos a mulher circunscrita no espaço determinado pelo patriarcalismo. Ao singularizar-se no nome Maria, o eu-poético se junta a tantas outras na mesma condição de subalternidade. Elas são comtempladas nos versos de:

\section{Tantas}

Ah! Com que alegria

me descubro Maria

como tantas mais.

8 Representações vindas do Paleolítico e do Neolítico índices importantes para a definição dessa figura feminina como a Deusa Mãe ou a Grande Mãe. Também representa a Mãe Terra: a Mãe Natureza, uma representação da Natureza que trata da fertilidade, dos ciclos e do cultivo simbolizados na mãe. 
E partilho com todas

a tolice de gostar de flores

e olhar pra lua

em busca de sinais.

Sou Maria cheia de crendices,

mania de fé.

No meu dia- a -dia tacanho

encontro portais,

quando falo às plantas,

arrumo a casa,

alimento os animais.

Sou Maria

De menos salário

em igual função.

Sou Maria

múltipla jornada

puta, mãe, salada

outra, esposa e pão.

(CARVALHO, 2007, p.30)

Novamente a poesia retoma a figura arquetípica da mulher como representação da religião judaica cristã e fica explícita a sua submissão ao patriarcado no poema intitulado Tantas, (p.30). A voz poética se descobre Maria e se reconhece no meio de outras tantas que se igualam não apenas no nome, mas no gênero, pois são todas "Marias" e partilham de tolices e crendices. O eu -poético diz; “Ah! Com que alegria/Me descubro Maria/Como tantas mais. /E partilho com todas/a tolice de gostar de flores/e olhar para a lua/em busca de sinais. [...]" (CARVALHO, 2007, p.30).

Estes versos retomam as características das tantas Marias que se descobrem mulheres e passam a partilhar dos mesmos gostos, mas o eu- luciênico, já afirma que se trata de tolices. Tolices que nos remetem ao patriarcado e a cultura judaica cristã que persiste em igualizar as mulheres na figura de Maria - A mãe de Jesus- mulher exemplar e dócil.

O eu - poético se posiciona sobre o papel destinado a mulher, herdado do patriarcalismo. Moureau (1974) apud Silveira (2017), diz que o cristianismo havia lançado um anátema sobre a mulher, censurando-lhe a impureza e renegando-a à inferioridade. Nos versos que seguem, a voz poética, tenta mostrar essa condição ínfera destinada a mulher: "No meu dia- a -dia tacanho/ encontro portais, / quando falo às plantas, / arrumo a casa, /alimento os animais." Ao poetizar o cotidiano das "Marias", Luciene Carvalho traz para sua poesia a luta diária de tantas mulheres invisíveis para a sociedade atual, pois ainda são muitas aquelas que se encontram presas nos lares, condicionadas aos serviços domésticos. Presas 
ainda? Umas talvez pela condição social e falta de oportunidades para estudar e atuar em profissões que lhes dessem visibilidade, outras quem sabe, pela imposição cultural e religiosa.

Para Drummond os obstáculos foram representados por uma pedra no meio do caminho, mas para mulher dona de casa, são os portais, pois sua caminhada é de um cômodo para outro, fazendo a faxina, organizando a casa ou indo para a lavanderia e, na correria esbarrando nos portais. "A história mostrou-nos que os homens sempre detiveram todos os poderes concretos; desde os primeiros tempos do patriarcado, julgaram útil manter a mulher em estado em estado de dependência;" (BEAUVOIR, 1949, p. 1949). O espaço do lar e os afazeres domésticos foram determinados historicamente pelo homem.

A escritora Luciene Carvalho transforma vivencias cotidianas em poesia e traz à tona também a condição da mulher dona de casa. Quando Todorov $(2009$, p. 77) afirma que a literatura é pensamento e conhecimento do mundo psíquico e social em que vivemos é porque a realidade que esta aspira é simplesmente a experiência humana.

E nos versos do poema "Tantas", o eu poético iguala-se a tantas "Marias" que no seu cotidiano conversam com plantas e poetizam seu dia minimizando o cansaço com atividades domésticas infindas. Para descrever o cotidiano das "Marias", Luciene organiza as palavras que representam as dificuldades dos afazeres domésticos, pois são respetivos e nunca terminam.

As rimas entre "mais", "sinais", "portais" e "animais" representam as dores, o cansaço dessas mulheres. Neste verso "como tantas mais", a palavra "mais" significa quantidade, entretanto, ao rimar com sinais, portais e animais passa a ser um intensificador das aflições cotidianas das mulheres do lar. Essa sonoridade reiterada remete aos intermináveis trabalhos domésticos que sempre tem mais, "ais", “ais", "ais" ...

A escrita poética de Luciene Carvalho estabelece conexão com as palavras de Candido, pois aquele "que faz poesia conhece o ritmo na natureza e pode tê-lo observado e imitado; e que a associação humana cria tipos de atividades ritmadas que incrementam este conhecimento do ritmo." (CANDIDO, 2006, p. 71). Assim, o ritmo tece uma teia de coesão no texto poético Luciênico.

Nos últimos versos o eu- poético é afirmativo e aponta para aceitação de sua condição de mulher do lar. O verbo ser, na primeira pessoa do singular, garante esta condição de 
mulher do lar, mãe esposa, visto que: "Sou Maria/ de menos salário/ em igual função9 . / Sou Maria/ múltipla jornada/ puta, mãe, salada/ outra, esposa e pão”.

Nas rimas entre as palavras jornada e salada o eu-poético denuncia que as "Marias" prestam outros serviços no espaço do lar. Hora é puta, hora é mãe, outra, esposa... Não tem horário definido para estes atendimentos, é "salada" misturada, na sua rotina diária, na múltipla jornada e sem definição exata de sua função.

Ao rimar função e pão o eu-poético se iguala a tantas que atuam nesta função, sendo o alimento, a força da mulher que permanece apenas enquanto trabalhadora do lar. Nota-se que o eu-poético Luciênico sabe da desvalorização que tem essa função e o desprestigio que lhe é atribuída pela sociedade e até mesmo, por parte da própria família que depende de seu trabalho. Entretanto, ela se reconhece como sustento, alimento para todos ao se colocar como pão. Por outro lado, a sonoridade produzida pelas palavras função e pão remete a negação das tantas Marias. O som repetitivo dos “ão”, “ão” sugere a imagem que grita Não.

\section{Considerações Finais}

A partir da análise dos poemas selecionados foi possível entrar em contato de forma aprofundada com o eu-poético e perceber, em certa medida, como a autora traz os arquétipos da mulher e o cotidiano feminino a sua arte. A este respeito, já firma Aristóteles que a poesia é uma imitação da natureza. De acordo com Todorov (2009, p. 66), o escritor necessita conhecer a realidade do mundo para imitá-la. Luciene Carvalho, em sua produção literária expressa a plena consciência desta realidade e faz o seu conhecimento do mundo transcender o comum para transformar-se em poesia. Cada verso luciênico toca-nos emocionalmente, impacta-nos de forma profunda e nos convoca à reflexão.

A literatura, segundo Candido (2002) é coletiva, na medida em que requer uma certa comunhão dos meios expressivos, e mobiliza afinidades profundas que congregam os homens de um lugar e de um momento, - para chegar a uma "comunicação". A voz poética Luciênica atinge o nível de comunicação entre escritor e leitor através da palavra diluída nos versos de seus poemas. É a voz que se ergue para despertar na mulher o desejo de se libertar do espaço circunscrito imposto pela cultura patriarcal e como Kilomba (2019), torna-se autora e a autoridade de sua própria história e oposição as predeterminações do colonialismo.

9 Grifo nosso: para destacar a rima produzida com as palavras: função com pão e a sonoridade repetitiva do "ão". 

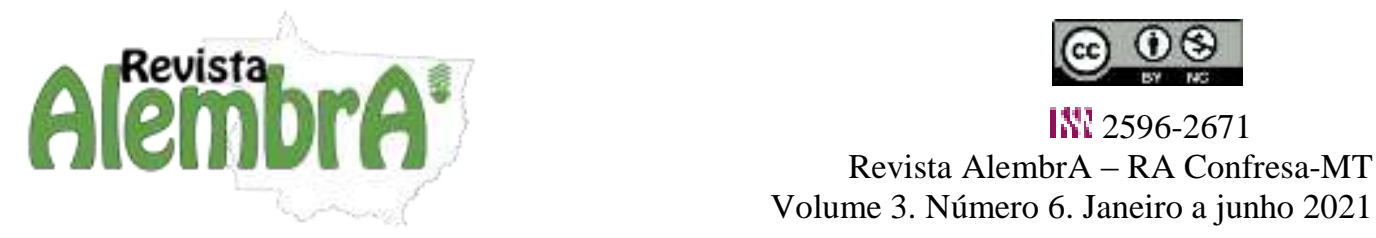

No nome "Maria" a poesia Luciênica revela as tantas mulheres que foram praticamente destituídas de suas identidades, pois se igualam no nome sendo "Marias" de dupla jornada. Denuncia que o espaço que foi determinado pela cultura patriarcal não pertence somente a mulher.

O eu- poético conseguiu se libertar da religião judaico-cristã que se utiliza da imagem de Maria, a "Santa", como modelo de mulher. Ao fazer banhos e mantras entrar para o Tarô o eu Luciênico revela a liberdade de escolha religiosa. A ideologia cristã contribuiu para a sujeição da mulher ao homem. Retomamos Simone Beauvoir (1949), no que concerne a imposição de docilidade e modéstia repetido nos discursos religiosos até hoje. Baseando-se no Antigo e Novo Testamento, Paulo exige o princípio se subordinação da mulher ao homem.

A segunda parte do título da obra traz o nome da mulher que aparece ao lado de Cristo: Madalena. Afinal, sejam elas Marias ou Madalenas seus nomes foram escritos na história representando tantas e como a primeira parte do título Aquelarre sugere que a mulheres se reúnam para aprender uma com a outra. No poema Mãe do mundo a poesia luciênica direciona a mulher para o encontro com a Deusa e a descoberta de que ela mora dentro de cada mulher. Em Tantas, elas Marias e Madalenas se reúnem, trocam conhecimentos, na luta se reconhecem.

A poesia enquanto instrumento vivo de comunicação transmitida pelo eu Luciênico, consubstancia-se em um convite à reflexão. Mulher e negra, Luciene de Carvalho, por meio da sua escrita impõe-se e torna-se sujeito de sua própria realidade. A escritora, pode-se dizer, em outras palavras, é um tronco poético que se ramifica, e desses ramos brotam palavras que se juntam para tornar-se poesia. Sua poesia imagética e intensamente contemplativa, apresenta-se opulenta e repleta de plurissignificação.

\section{Referências}

ALMEIDA, Sandra Regina Goulart. Prefácio- Apresentando Spivak. In: SPIVAK, Gayatri Chakravorty. Pode o Subalterno Falar? Tradução: ALMEIDA, Sandra Regina Goulart, et. al. 2. Reimpressão. Belo Horizonte: Editora UFMG, 2014.

BELL HOOKS. Intelectuais negras. Periódicos UFSC: Santa Catarina 1995. Disponível em: https://periodicos.ufsc.br/index.php/ref/article/view/16465/15035. Acesso em 23/06/2021.

BOSI, Alfredo. O ser e o tempo da poesia. São Paulo: Cultrix, 1977. 275 p. 
CANDIDO, Antonio. Literatura e Sociedade: estudos de teoria e história literária. 8. Ed. São Paulo: T. A. Queiroz, 2000. 195 p.

CANDIDO, Antonio. O estudo analítico do poema. São Paulo: Humanitas Publicações, 2006. 164 p.

CARVALHO, Luciene. Aquelarre ou livro de Madalena. Cuiabá: Instituto Usina, 2007.

CARVAlHO, Maria da Penha Felicio dos Santos de; et al. O Ponto de Vista Feminino na Reflexão Ética: Histórico e Implicações para a Teoria de Organizações. Disponível: www.anpad.org.br > pdf > enanpad2001-teo-8. Acesso: 18/03/2021.

COMPAGNON, Antoine. O Demônio da Teoria: literatura e senso comum. 2.ed. Belo Horizonte: UFMG, 1999. 305 p.

GOLDSTEIN, Norma Seltzer. Versos e rimas. Ed.14.rev. e atualizada. São Paulo: Ática, 2006.

KILOMBA, Grada. Memórias da Plantação: Episódios de racismo no cotidiano. Rio de Janeiro: Cobogó. 2019. 249 p.

LIMA, Andressa Bessa Machado et.al. O espaço da mulher na sociedade: uma reflexão a partir de o Segundo Sexo de Simone de Beauvoir. Revista AlembrA: Confresa-MT. Volume 1. Número 3. Julho a Dezembro 2019.

MARQUETTI, Flávia Regina. (2003). A protofiguratividade da Deusa Mãe. Clássica Revista Brasileira De Estudos Clássicos, São Paulo, v. 15/16, n. 15/16, p. 17-40, 2002/2003. Disponível em: https://doi.org/10.24277/classica.v15i15/16.224. Acesso em: 17/10/2019.

MOREIRA, Ana. Apresentação do livro. In: CARVALHO, Luciene. Aquelarre ou livro de Madalena. Cuiabá: Instituto Usina, 2007.

MOTA-Ribeiro, S. 'Ser Eva e dever ser Maria: paradigmas do feminino no Cristianismo', comunicação apresentada ao IV Congresso Português de Sociologia, Universidade de Coimbra, 17-19 de abril, 2000. Disponível em: https://www.academia.edu/33024801/Acesso em: 10/09/2019.

PERRONE-MOISÉS, Leyla. A criação do texto literário. In: PERRONE-MOISÉS, Leyla. Flores na escrivaninha. São Paulo: Companhia das Letras, 2006, p. 100-110.

ROMANELLI, Marina. A representatividade feminina na literatura brasileira contemporânea. Rio de Janeiro, 2014. UFRJ/ECO, 51f. Escola de Comunicação, Universidade Federal do Rio de Janeiro, Rio de Janeiro, 2014.

SILVEIRA, Diego Omar da. Mulher, mãe e esposa: conservadorismo católico e representações do feminino na imprensa católica mineira. ProPosiç̃es: vol.28 no.3. Campinas set./dez. 2017. Disponível: $\quad$ http://dx.doi.org/10.1590/1980-6248-2016-0110. Acesso em 10/09/2019. 
TODOROV, Tzvetan, 1939- A literatura em perigo! tradução Caio Meira. - Rio de Janeiro: DIFEL, 2009. 96 p.

SIGNIFICADO- Lemniscata. Disponível em: https://www.significados.com.br/oito-deitado/. Acesso em: 13/04/2021.

SPIVAK, Gayatri Chakravorty. Pode o Subalterno Falar? Tradução: ALMEIDA, Sandra Regina Goulart, [et. al.] 2. Reimpressão. Belo Horizonte: Editora UFMG, 2014.

WOOLF, Virginia. Um teto todo seu. 1. Ed. São Paulo: Tordesilhas, 2014.

REVISTA NA BALANÇA. Entrevista com Luciene Carvalho. Editada na FD/UFMT Ed.2, Agosto, 2020. Disponível: Na Balança agosto de 2020 BÔNUS- Luciene Carvalho.pdf. Acesso em: 21/08/2020. 